\title{
COMPLEMENTARY AND ALTERNATIVE MEDICINE: WHAT IS IT ALL ABOUT?
}

ong a source of primary care in most countries, complementary/alternative medicine (CAM) has recently become a focus of interest in industrialised nations. ${ }^{12}$ Terms often used synonymously -reflect conflicting perspectives. Proponents may prefer the terms holistic, natural, non-toxic, integrative, médecine douce (gentle medicine); opponents employ the words unproven, unscientific, fringe, non-traditional, or "Außenseitermedizin" (outsiders' medicine). Perhaps the most neutral terms are "practiques paralleles" (parallel practices), unconventional, or complementary medicine. "Alternative medicine" is more widely used in the USA (it is also the term employed by Medline), "complementary medicine" in the UK. We consider the latter most accurate but bow to the current convention of referring to CAM.

The aim of this article is to provide a short general introduction to CAM. It is written predominantly with occupational and environmental healthcare professionals in mind; its aim is to familiarise them with this increasingly important topic.

\section{DEFINITION}

Complementary therapies seem to have little in common other than their exclusion from the mainstream. Many supporters are convinced of the superiority and universal applicability of their treatment. CAM encompasses primary care systems of medicine (including traditional Chinese medicine and Ayurvedic medicine, which have unique diagnostic criteria and diverse therapeutic options), discrete therapies ( shark cartilage, bee pollen, ozone therapy, etc) and almost everything in between. Besides comprising over 150 treatment modalities, ${ }^{3}$ CAM also embraces a large variety of diagnostic methods. ${ }^{4}$ A positive definition, describing CAM by what it is rather than by what it is not, has recently been adopted by the Cochrane Collaboration: CAM is diagnosis, treatment and/or prevention which complements mainstream medicine by contributing to a common whole, by satisfying a demand not met by orthodoxy or by diversifying the conceptual frameworks of medicine. $^{4}$

\section{HISTORY}

Both in Europe ${ }^{5}$ and the USA ${ }^{6}$ CAM has enjoyed periods of popularity only to cycle into disfavour later. For example, in the USA during the mid to late 19th century, homeopathy, hydropathy (water cures), Thomsonianism (a system which included dietary changes, herbalism, and steam baths based on the teachings of Samuel Thomson) and Eclecticism (the precursor of today's naturopathy) all thrived, only to dwindle into obscurity in the 20th century. ${ }^{7}$ Sir William Osler's Principles and practice of medicine, first published in 1892, recommended acupuncture for sciatica and lumbago; the reference was expunged 30 years after Osler's death in $1919 .{ }^{8}$

Neither prevalence of use nor patient satisfaction are acceptable surrogates for efficacy. If CAM is to have a lasting effect on the provision of health care, a sound evidence base must be established. Such an evidence base would be in the interest of the patient. It presents quite simply the only way to make sure that CAM is doing more good than harm. ${ }^{2}$

\section{PRESENT PREVALENCE}

A telephone survey of more than 1500 adults in the USA demonstrated that $~ 33 \%$ had used a complementary therapy in 1990; by 1997 the figure had risen to about $42 \%{ }^{9}$

Lifetime prevalence is in excess of $60 \% .{ }^{10}$ In 1990 , the number of visits to CAM practitioners in the USA roughly equalled that to primary care physicians. In 1997 the former outnumbered the latter by about $70 \%$.

In other industrialised countries, CAM is even more popular. Between 20-65\% of the general populations in Europe are using some form of CAM. ${ }^{11-13}$ The use of CAM in non-industrialised countries may be ubiquitous; the World Health Organization (in an oft-invoked statement with no primary reference) claims that $80 \%$ of the world depends on indigenous therapies. ${ }^{14}$

To date there is virtually no evidence regarding the provision of CAM through occupational health departments in the UK or elsewhere. Extrapolating from the most important indications for 
Box 1 Conditions most frequently treated with complementary therapies (in descending order)

\begin{tabular}{lll}
\hline USA 1990* & USA 1997† & UK 1994‡ \\
\hline Low back pain & Neck problems & Low back pain \\
Anxiety & Back problems & Other pain \\
Headache & Anxiety & Psychological illness \\
Chronic pain & Depression & Gynaecological conditions \\
Cancer/tumour & Headache & Respiratory conditions \\
Depression & Digestive problems & Arthritis \\
Insomnia & Fatigue & ME and fatigue \\
\hline
\end{tabular}

*Data from Eisenberg et al. ${ }^{9}$

†Data from Berg et al. ${ }^{10}$

$\ddagger$ Own data

$\mathrm{ME}$, myalgic encephalomyelitis (chronic fatigue syndrome)

CAM (box 1), one might expect that such units frequently consider some form of CAM or another. Anecdotally we know that UK occupational health departments are increasingly being asked to provide or facilitate some forms of CAM, for instance for employees. Reliable data regarding the extent to which CAM is available in such departments should now be gathered.

\section{REASONS FOR USE}

The high prevalence of CAM usage worries some and reassures others. In any case, it clearly begs the question, why do so many people turn to CAM? While reasons may differ vastly from one sample of users to another, several recurring themes seem to emerge..$^{15-17}$

\section{Expansion of diagnostic options}

A disparate collection of symptoms that fits no syndrome known to conventional medicine may be a perfect fit for a traditional Chinese medicine or a homoeopathic diagnosis. Recognising — and naming — a disease can be a major source of validation and relief to a patient. Donning an alternative diagnostic label can renew hope, maximising receptivity to CAM treatments, regardless of whether or not the diagnostic method used is valid or not.

\section{Expansion of therapeutic options}

Patients who use CAM do so most often at opposite ends of the disease spectrum: either for chronic, minor illnesses (for example, back pain) or for devastating, life threatening conditions (for example, cancer). In both situations, conventional options may be perceived as either ineffective and/or too toxic. Besides perceived therapeutic benefits, many complementary therapies not only have few unpleasant adverse effects but actually have pleasant side effects-for example, a massage therapy for musculoskeletal pain can be very relaxing to the mind. The aims of CAM may be closer to those of patients than doctors; while physicians usually want to alter the course of pathological processes, patients simply want to feel better.

\section{Psychological distress}

A recent and potentially important finding indicates that, in severely ill patients, the use of CAM might be a marker for distress. A prospective study was conducted of how psychology influenced the usage of CAM in breast cancer patients. Three months after the diagnosis, those women who had chosen to try CAM had more evidence of depression, lower levels of sexual satisfaction, a greater fear of recurrence of disease, as well as more frequent and severe symptoms. ${ }^{18}$

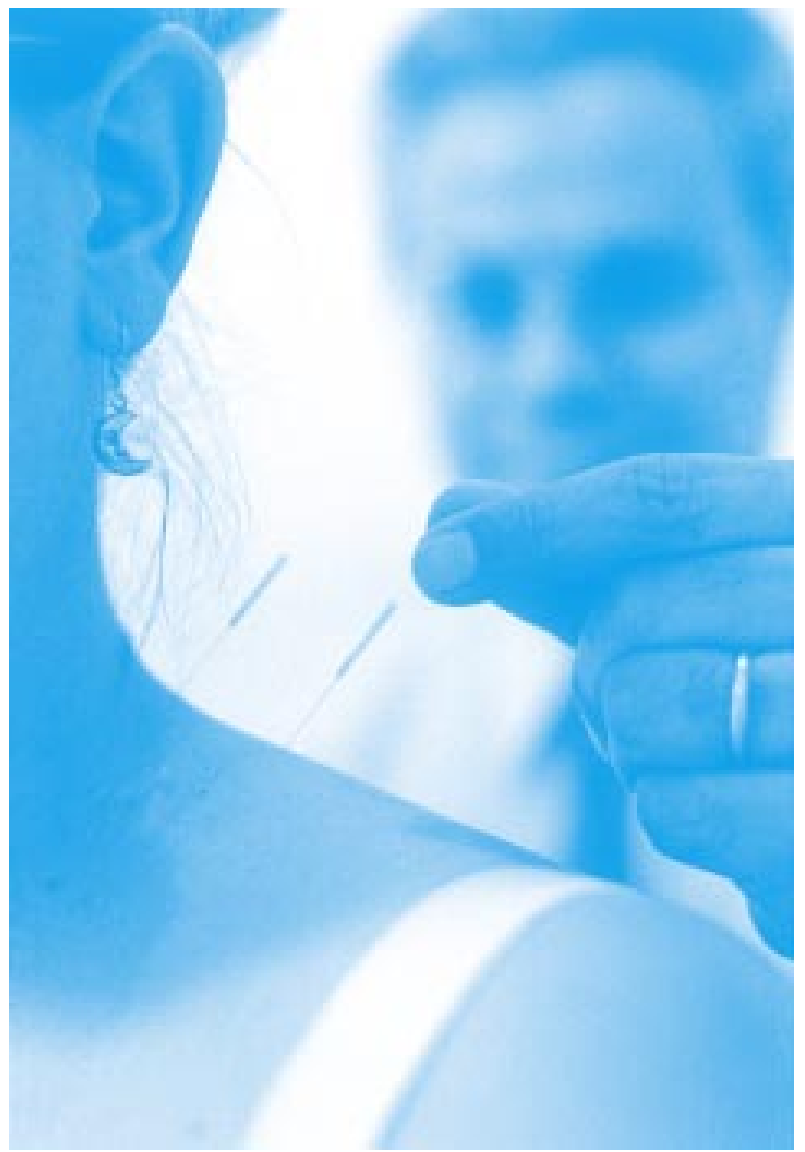

Sir William Osler's Principles and practice of medicine, first published in 1892, recommended acupuncture for sciatica and lumbago. Photograph courtesy of Royal London Homoeopathic Hospital.

\section{Better patient-provider relationship}

It is here that conventional medicine should accept culpability; many of us are palpably bored by the management of chronic problems (which, though not medically "serious", significantly affect the lives of our patients). When we exhaust our therapeutic repertoire in a terminal illness, we may turn our attention elsewhere. Whenever we cannot cure, we tend to fall short in our other duty: to care. It is hardly surprising then that many patients experience the therapeutic relationship with CAM practitioners more rewarding.

Survey data seem to confirm these diverse motivations for trying CAM. Patients from three different European nations thought that the most frequently named reasons for trying CAM were: the desire to use all possible options of healthcare; the hope of being cured without side effects; previous good experience; and the use of CAM as a last hope. ${ }^{17}$

\section{INDICATIONS}

The conditions most commonly treated by CAM are listed in box 1 . It has been wryly pointed out that for conditions where mainstream medicine offers a cure, CAM has no followers. ${ }^{19}$ The offer of hope is a seductive incentive. CAM thrives where (depending on one's point of view) mainstream medicine has failed or no effective treatments exist. In truth these categories overlap. This also points up the dissatisfaction of patients with conventional therapies (and perhaps conventional therapists) for these conditions. 
Box 2 Clinical trial evidence in complementary medicine: conclusions from recent, authoritative meta-analyses and systematic reviews

\begin{tabular}{|c|c|c|c|}
\hline & Acupuncture & Homoeopathy & Manipulation \\
\hline Conditions & Chronic pain & Any & Low back pain \\
\hline Type of data summarised & 14 RCTs of various forms of acupuncture & $\begin{array}{l}89 \text { randomised and/or placebo } \\
\text { controlled trials }\end{array}$ & 8 RCTs of chiropractic \\
\hline Method of evaluation & Systematic review & Meta-analysis & Systematic review \\
\hline Conclusion (verbatim quotes) & $\begin{array}{l}\text { There is limited evidence that acupuncture is } \\
\text { more effective than no treatment for chronic } \\
\text { pain and inconclusive evidence that } \\
\text { acupuncture is more effective than placebo, } \\
\text { sham acupuncture or standard care }\end{array}$ & $\begin{array}{l}\text { Clinical effects of homoeopathy } \\
\text { are [not] completely due to } \\
\text { placebo }\end{array}$ & $\begin{array}{l}\text { [No] convincing evidence for the } \\
\text { effectiveness of chiropractic for } \\
\text { acute or chronic low back pain }\end{array}$ \\
\hline Reference & Ezzo et $a^{\beta 3}$ & Linde $D$ et $a^{\beta 4}$ & Assendelft et $a^{\beta 5}$ \\
\hline
\end{tabular}

In the case of life threatening disease, the potential for exploitation of the patient is, of course, greatest. ${ }^{20}$ On the one hand, the use of CAM for serious disease could mean that CAM merely sells hope (at times irresponsibly) where no effective treatments are available. On the other hand, it suggests that CAM is operating in an area where therapeutic success is difficult, mainstream medicine has failed, and any benefit at all would be precious.

\section{ATTITUDES WITHIN CONVENTIONAL MEDICINE}

In the aforementioned surveys, ${ }^{9} 72 \%$ of those seeing an alternative practitioner did not tell their physician that they were doing so. While patients may have feared censure, their physicians (especially family practitioners) may be more open minded than they think. A survey of 594 US family physicians found that $44 \%$ of these doctors thought faith healers and physicians could work together to cure some patients, and $23 \%$ believed that faith healers heal some patients whom physicians cannot help. ${ }^{21}$

A survey of 138 community physicians in Washington State, New Mexico, and southern Israel found that more than $60 \%$ of all doctors had made referrals to CAM practitioners in the last year and $38 \%$ in the preceding month. ${ }^{22}$ Of 200 Canadian general practitioners, 54\% referred to CAM practitioners and $16 \%$ practised some form of CAM. ${ }^{23}$ Seventeen per cent of Israeli family physicians have formal training in at least one form of CAM, and $42 \%$ refer patients for such treatments. ${ }^{24}$ Those physicians who incorporate one form of CAM into their practice are likely to use or refer patients for other CAM treatments. $^{25}$

Physicians and medical students are clearly interested in learning more. ${ }^{26}$ Many US medical schools are now offering elective courses in CAM. ${ }^{27}$ In the UK, 15 of all 23 medical schools now offer elective courses in $\mathrm{CAM}^{28}$ and one medical faculty recently instituted a compulsory course on CAM for all undergraduate medical students. ${ }^{29}$ The extent to which CAM is integrated into the education of occupational and environmental medicine has so far not been investigated.

Two independent surveys have investigated what evidence decision makers within the British National Health Service require for purchasing CAM. ${ }^{30}{ }^{31}$ The two items ranked highest were proof of efficacy (through randomised controlled trials (RCTs)) and safety. Evidence based medicine, it seems, will not bypass CAM.

\section{HAS CAM AN EVIDENCE BASE?}

This article cannot be the place to provide an in-depth, comprehensive review of the evidence relating to CAM. Numerous RCTs are available and several systematic reviews or meta-analyses of RCTs have been published (for example, Ernst and colleagues ${ }^{32}$ ). A list of $\sim 60$ systematic reviews published by the team of the first author can be ordered from him free of charge. Such critical evaluations of the existing evidence may come to sobering conclusions (box 2). ${ }^{33-35}$ For instance, contrary to what many believe and what practice guidelines tell us, chiropractic is not proven beyond reasonable doubt to be effective for low back pain. ${ }^{35}$ One ought to remember, however, that absence of evidence must not be equated with evidence for absence of efficacy (or safety). In other areas, particularly herbal medicine, the evidence base is firstly more solid and secondly frequently compellingly positive. ${ }^{32}$ Box 3 summarises the evidence available to date $e^{32}$ for two conditions frequently encountered in occupational and environmental medicine: back pain and anxiety.

Box 3 The evidence base for CAM using the examples of back pain and anxiety

\begin{tabular}{lll}
\hline Therapy & Back pain & Anxiety \\
\hline Acupuncture & Substantial amount of RCTs, overall result tentatively positive & Insufficient data \\
Aromatherapy & Insufficient data & Several RCTs, overall result tentatively positive \\
Autogenic training & Insufficient data & Several RCTs, overall result tentatively positive \\
Biofeedback & Insufficient data & Several RCTs, overall result not clear \\
Herbal medicine & Devil's claw: few RCTs, overall result positive & Kava: satisfactory amount of RCTs, overall result positive \\
Homoeopathy & Insufficient data & Insufficient data \\
Hypnotherapy & Insufficient data & Insufficient data \\
Massage & Few RCTs, overall result tentatively positive & Few RCTs, overall result tentatively positive \\
Meditation & Insufficient data & Several RCTs, overall result positive \\
Relaxation & Insufficient data & Several RCTs, overall result positive \\
Spinal manipulation & Substantial amount of RCTs, overall tentatively positive for & Few RCTs, overall result negative \\
Spiritual healing & acute back pain and less clear for chronic back pain & Insufficient data \\
\hline
\end{tabular}

Evidence based on systematic reviews summarised in Ernst et al. ${ }^{32}$ 
Box 4 Safety of complementary therapies

\begin{tabular}{|c|c|c|c|}
\hline & Acupuncture & Homoeopathy & Manipulation \\
\hline $\begin{array}{l}\text { Examples of serious adverse } \\
\text { effects }\end{array}$ & Trauma, infections & Allergies & Fractures, stroke \\
\hline Fatalities reported? & Yes & No & Yes \\
\hline $\begin{array}{l}\text { Frequency of adverse effects } \\
\text { known? }\end{array}$ & No & No & No \\
\hline Complication avoidable? & No* & No & Not \\
\hline Indirect safety issues & $\begin{array}{l}\text { - Potentially applic } \\
\text { - Missed diagnose } \\
\text { - Misdiagnoses } \\
\text { - Disregarding cor } \\
\text { - Discontinuation, } \\
\text { - Potentially hazar }\end{array}$ & $\begin{array}{l}\text { complementary } \\
\text { ions } \\
\text { /delay of effectiv } \\
\text { nostic procedures }\end{array}$ & py \\
\hline \multicolumn{4}{|c|}{$\begin{array}{l}\text { *Yes in case of infection. } \\
\text { †Fracture rates might be minimised by excluding high risk patients (for example, menopausal } \\
\text { women). } \\
\text { Evidence presented in this table is based on Ernst et al, }{ }^{32} \text { Assendelft et al, }{ }_{1}^{35} \text { and Ernst et al. }{ }^{37}\end{array}$} \\
\hline
\end{tabular}

In addition to efficacy, safety of CAM has to be considered. The truly relevant question relates neither to efficacy nor to safety in isolation but asks: does it do more good than harm? Many users of CAM are convinced that CAM is totally devoid of adverse effects. CAM is (perceived as) natural, and "natural" implies "no side effects". This media hyped misunderstanding ${ }^{36}$ can be dangerously wrong. Most, if not all, therapies have direct risks and adverse effects (for example, Ernst and colleagues ${ }^{32}$ ). Serious complications are being reported with depressing regularity but, at present, we cannot reliably define their frequency (box 4).

There are also indirect risks of CAM such as misdiagnoses, disregard of contraindications, hindering access to effective orthodox interventions, or potentially harmful diagnostic practices associated with a given type of therapy. ${ }^{32}{ }^{37}$ This issue is particularly delicate since it borders on the following question: who is medically competent to take responsibility for patients and who is not? ${ }^{36}$ Competence can best be achieved by proper training and sufficient experience. Whenever training is insufficient, serious adverse effects are likely. Insufficient training or education may be a problem both with conventional healthcare professionals (who may not be properly trained in CAM procedure) or non-medically qualified CAM practitioners (who may not have sufficient medical knowledge in anatomy, physiology, pathology, etc).

A solid evidence base should also contain data on the cost of CAM. Many proponents intuitively feel that CAM has the potential to save money for our healthcare systems in the long run. Sadly this is, so far, not supported by convincing evidence. A recent systematic review of all economic evaluations of CAM showed that investigations with flawed methodology tended to suggest that the use of CAM saves money. However, the more rigorous studies implied that this is, in fact, not true and that expenditure for CAM represents an add-on cost. ${ }^{38}$

\section{CONCLUSION}

CAM is an important topic not least because a large proportion of our patients turn towards it. There are many reasons to explain this phenomenon; in part they represent a serious criticism of orthodox medicine. The evidence base for CAM is growing but in most areas it is insufficient for making sound risk/benefit assessments. It follows that further research is needed to fill these all too obvious gaps and that the funds to carry out this work have to be found.

\section{REFERENCES}

1 Jonas WB. Alternative medicine - learning from the past, examining the present, advancing the future. JAMA 1998;280:1616-18.

\section{Summary}

Complementary/alternative medicine (CAM) has become popular, and many professionals working in occupational and environmental medicine feel the need to learn more about it. This article briefly discusses the definition of CAM, its history, its high level of acceptance by the general public, the reasons why people try CAM, its indications, the attitudes of conventional healthcare professionals towards CAM, and the question of whether a sound evidence base for CAM exists. It is concluded that CAM is an increasingly important, albeit under researched, subject. Further rigorous investigations should address the many open questions, and funds to carry out this research have to be found.

2 British Medical Association. Complementary medicine, new approaches to good practice. Oxford: Oxford University Press, 1993.

3 Ernst E, Hentschel $\mathrm{CH}$. Diagnostic methods in complementary medicine. Whichcraft or witchcraft? Int J Risk Saf Med 1995;7:55-63.

4 Ernst E, Resch KL, Mills S, et al. Complementary medicine - a definition. $\mathrm{Br}$ J Gen Pract 1995;45:506.

5 Kaptchuk TJ. Historical context of the concept of vitalism in complementary and alternative medicine. In: Micozzi MS, ed. Fundamentals of complementary and alternative medicine. New York: Churchill Livingstone, 1996.

6 Ernst E. Naturheilkunde im Dritten Reich. Deutsches Arzteblatt 1995;92:800-4

7 Duffy J. Irregulars and domestic practitioners. From humors to medical science: a history of American medicine. Chicago: University of Illinois, 1993.

8 Lytle CD. An overview of acupuncture. Rockville, Maryland: Center for Devices and Radiological Health, Food and Drug Administration, Public Health Service, 1993

9 Eisenberg D, David RB, Ettner SL, et al. Trends in alternative medicine use in the United States, 1990-1997. JAMA 1998;280:1569-75.

- An important set of two identical US surveys showing a substantial increase in popularity of CAM.

10 Burg MA, Hatch RL, Neims AH. Lifetime use of alternative therapy: a study of Florida residents. Southern Med J 1998;91:1126-31.

11 Ernst E, White AR. The BBC survey of complementary medicine use in the UK. Complement Ther Med 2000;8:32-6.

12 Fisher $\mathbf{P}$, Ward A. Complementary medicine in Europe. BM 1994;309:107-11.

13 Häusermann D. Wachsendes Vertrauen in Naturheilmittel. Dtsch Ärzteblatt 1997;94:1857-8.

14 Farnsworth NR, Akerele O, Bingel AS, et al. Medicinal plants in therapy. Bull World Health Org 1985;63:965-81.

15 Astin JA. Why patients use alternative medicine. Results of a national study. JAMA 1998;279:1548-53.

16 Vincent C, Furnham A. Why do patients turn to complementary medicine? An empirical study. Br J Clin Psychol 1996;35:37-48.

17 Ernst E, Willoughby M, Weihmayr TH. Nine possible reasons for choosing complementary medicine. Perfusion 1995;8:356-8.

18 Burstein HJ, Gelber SG, Guadagnoli E, et al. Use of alternative medicine by women with early-stage breast cancer. N Engl J Med 1999;240:1733-9.

19 Cassileth BR, Lusk EJ, Strouse TB, et al. Contemporary unorthodox treatments in cancer medicine. Ann Intern Med 1984;101:105-12. 
20 Ernst E. Complementary cancer treatments, hope or hazard? Clin Oncol 1995; 7:259-63.

21 King DE, Sobal J, Haggerty J, et al. Experiences and attitudes about faith healing among family physicians. J Fam Pract 1992;35:158-62.

22 Borkan J, Neher JO, Anson O, et al. Referrals for alternative therapies. J Fam Pract 1994:39:545-50.

23 Verhoef MJ, Sutherland LR. Alternative medicine and general practitioners: opinions and behavior. Can Fam Phys 1995;41:1005-11. nonconventional therapies. Arch Fam Med 1993;2:1268-70.

25 Dichtl DL, Caplan I, Glik D, et al. Use of acupuncture by American physicians. J Alt Comp Med 1997;3:1 19-26.

26 Ernst E. Medical students' attitudes towards complementary medicine: systematic review. Student BM. 1998;6:204-6.

27 Daly $\mathbf{D}$. Alternative medicine courses taught at US medical schools: an ongoing listing. J Alt Comp Ther 1996;2:315-17.

28 Anon. Education and training. Integrated Health (FIM newsletter) 1999;1:3.

29 Hughe J. Medical schools embrace New Age. The Independent on Sunday, 1 August 1999, p 8

30 Van Haslelen $\mathbf{R}$, Fisher $P$. Evidence influencing British health authorities decisions in purchasing complementary medicine. JAMA 1998;290:1564.

31 Ernst E, Armstrong NC, White AR, et al. Research is needed to determine how to integrate complementary medicine into the NHS. BM 1998;317:1654.

32 Ernst E, Pittler MH, Stevinson C, et al. The desktop guide to complementary and alternative medicine. Edinburgh: Mosby, 2001

- A rigorously evidence based reference text for orthodox healthcare professionals.

33 Ezzo J, Berman B, Hadhazy VA, et al. Is acupuncture effective for the treatment of chronic pain? A systematic review. Pain 2000;86:217-25.

- A state of the art review of the evidence as it pertains to acupuncture as a treatment for chronic pain.

34 Linde K, Claudius N, Ramirez G, et al. Are the clinical effects of homoeopathy placebo effects? A meta-analysis of placebo controlled trials. Lancet 1997;350:834-43.

- A landmark meta-analysis of all rigorous trials of homoeopathy.

35 Assendelft WJJ, Koes BW, van der Heijden GJMG, et al. The effectiveness of chiropractic for treatment of low back pain: an update and attempt at statistical pooling. J Manipul Physiol Ther 1996;19:499-507.

- A critical review of adverse effects associated with CAM.

36 Ernst E, Weihmayr T. UK and German media differ over complementary medicine. BM 2000;321:707.

37 Ernst E. Risks associated with complementary therapies. In: Dukes MNG Aronson JK, eds. Meyler's side effects of drugs, 14th ed. Elsevier Science, 2000:1649-1681.

- A thorough review of adverse effects associated with CAM.

38 White AR, Ernst E. Economic analysis of complementary medicine: a systematic review. Complement Ther Med 2000;8:111-18.

\section{QUESTIONS (SEE ANSWERS ON P 84)}

(1) Which of the following statements are true about the background of complementary therapies?

(a) Complementary medicine is generally abbreviated to CAM

(b) Complementary therapies are, by definition, whole systems of medicine

(c) The Cochrane Collaboration defines complementary medicine as 'medicine not taught in medical schools'

(d) Acupuncture was recommended in the west in the early 20th century for treating back pain.

(2) Which of the following statements about the use of complementary medicine are true?

(a) In Britain today, the majority of the population have used complementary medicine sometime in their lives

(b) The World Health Organization claims that $80 \%$ of the world's population relies on indigenous therapies

(c) In the USA, visits to complementary therapists reach nearly half the number of visits to primary care physicians

(d) Most patients who use complementary medicine tell their physicians about it

(3) Which of the following statements about reasons for using complementary medicine are true?

(a) People prefer to have care they can pay for

(b) Patients seek to expand their diagnostic and therapeutic options

(c) People with more distress are more likely to use complementary medicine

(d) People use complementary medicine in the hope of being cured without suffering adverse effects

(4) Which of the following statements about doctors' attitudes to complementary medicine are true?

(a) In Canada, 26\% of physicians practise some form of complementary medicine

(b) More than half UK medical schools now offer elective courses in complementary medicine

(c) Because of the special nature of complementary medicine, evidence that patients enjoy the treatment is likely to be more valuable in determining priorities than evidence of efficacy and safety.

(d) Because it is natural, complementary medicine is, by definition, safe medicine.

(5) Which of the following statements about the evidence base of complementary medicine are true?

(a) There is no evidence that acupuncture is more effective than no treatment for chronic pain

(b) The clinical effects of homoeopathy are due to placebo

(c) There is convincing evidence for the effectiveness of chiropractic for acute or chronic low back pain

(d) Acupuncture and manipulation are known to have caused fatalities 